\title{
Correction to: Journal of Signal Processing Systems, Volume 91, issue 10
}

\author{
Springer Nature
}

(C) Springer Science+Business Media, LLC, part of Springer Nature 2019 / Published online: 19 November 2019

\author{
Correction to: J Sign Process Syst (2019) 91(10) \\ https://doi.org/10.1007/s11265-019-01479-0 \\ https://doi.org/10.1007/s11265-018-1401-8 \\ https://doi.org/10.1007/s11265-018-1404-5 \\ https://doi.org/10.1007/s11265-018-1409-0 \\ https://doi.org/10.1007/s11265-018-1406-3 \\ https://doi.org/10.1007/s11265-018-1407-2 \\ https://doi.org/10.1007/s11265-018-1405-4 \\ https://doi.org/10.1007/s11265-018-1420-5 \\ https://doi.org/10.1007/s11265-018-1419-y \\ https://doi.org/10.1007/s11265-018-1429-9 \\ https://doi.org/10.1007/s11265-018-1433-0
}

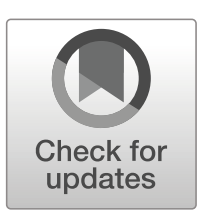

The online version of the original articles can be found at https://doi.org/10.1007/s11265-019-01479-0 https://doi.org/10.1007/s11265-018-1401-8 https://doi.org/10.1007/s11265-018-1404-5 https://doi.org/10.1007/s11265-018-1409-0 https://doi.org/10.1007/s11265-018-1406-3 https://doi.org/10.1007/s11265-018-1407-2 https://doi.org/10.1007/s11265-018-1405-4 https://doi.org/10.1007/s11265-018-1420-5 https://doi.org/10.1007/s11265-018-1419-y https://doi.org/10.1007/s11265-018-1429-9 https://doi.org/10.1007/s11265-018-1433-0 https://doi.org/10.1007/s11265-019-1438-3 https://doi.org/10.1007/s11265-019-1444-5 https://doi.org/10.1007/s11265-019-01461-w https://doi.org/10.1007/s11265-019-01459-4 https://doi.org/10.1007/s11265-019-01463-8 https://doi.org/10.1007/s11265-019-01468-3.

\section{Springer Nature}

\author{
https://doi.org/10.1007/s11265-019-1438-3 \\ https://doi.org/10.1007/s11265-019-1444-5 \\ https://doi.org/10.1007/s11265-019-01461-w \\ https://doi.org/10.1007/s11265-019-01459-4 \\ https://doi.org/10.1007/s11265-019-01463-8 \\ https://doi.org/10.1007/s11265-019-01468-3
}

The Publisher regrets an error on the printed front cover of the October 2019 issue. The issue numbers were incorrectly listed as Volume 91, Nos. 10-12, October 2019. The correct number should be: "Volume 91, No. 10, October 2019".

1 New York, NY, USA 